Engineering meter-scale laser resistant coatings for the near IR

C. J. Stolz, J. J. Adams, M. D. Shirk, M. A. Norton, T. L. Weiland

September 10, 2005

SPIE Optical Systems Design 2005

Jena, Germany

September 12, 2005 through September 16, 2005 
This document was prepared as an account of work sponsored by an agency of the United States Government. Neither the United States Government nor the University of California nor any of their employees, makes any warranty, express or implied, or assumes any legal liability or responsibility for the accuracy, completeness, or usefulness of any information, apparatus, product, or process disclosed, or represents that its use would not infringe privately owned rights. Reference herein to any specific commercial product, process, or service by trade name, trademark, manufacturer, or otherwise, does not necessarily constitute or imply its endorsement, recommendation, or favoring by the United States Government or the University of California. The views and opinions of authors expressed herein do not necessarily state or reflect those of the United States Government or the University of California, and shall not be used for advertising or product endorsement purposes. 


\title{
Engineering meter-scale laser resistant coatings for the near IR
}

\author{
Christopher J. Stolz, John Adams, Michael D. Shirk, Mary A. Norton, and Timothy L. Weiland \\ University of California, Lawrence Livermore National Laboratory, \\ 7000 East Avenue L-491, Livermore, CA 94550
}

\begin{abstract}
Laser resistant coatings are needed for beam steering (mirrors), pulse switching (polarizers), and high transport efficiency on environmental barriers (windows / lenses) on large laser systems. A range of defects limit the exposure fluence of these coatings. By understanding the origin and damage mechanisms for these defects, the deposition process can be optimized to realize coatings with greater laser resistance. Electric field modeling can provide insight into which defects are most problematic. Laser damage growth studies are useful for determining a functional laser damage criteria. Mitigation techniques such as micro-machining with a single-crystal diamond cutting tool or short pulse laser ablation using the burst technique can be used to arrest growth in damage sites to extend optic lifetime.
\end{abstract}

Keywords: Laser damage, optical thin films, electric field, defects, damage mitigation, $\mathrm{HfO}_{2}, \mathrm{SiO}_{2}$

\section{INTRODUCTION}

Mirrors and polarizers are typically used in laser systems for beam steering, pulse trapping, and parasitic isolation. The requirements for these coatings are low coating stress and high uniformity for minimal wavefront distortion, high reflectivity or transmission for low transport loss, and high laser resistance to minimize beam dimensions. Manufacturing high fluence mirrors is particularly challenging for large-aperture laser systems such as the National Ignition Facility (NIF) with a beam aperture of $40 \mathrm{~cm} \mathrm{x} 40 \mathrm{~cm}$ due to the high amount of surface area. ${ }^{1-2}$ Specifically, the large-aperture NIF mirrors have a combined surface area of $460 \mathrm{~m}^{2}$ of high-damage-threshold precision coatings on 100 tons of BK7. This optical surface area is equivalent to the combined surface area of eight Keck primary mirrors.

The large-aperture and high-fluence requirements have dictated selection of electron beam (e-beam) deposition as the coating method. Although promising results have been observed for Ion Beam Sputtering (IBS), scaling the IBS process to optics as large as $40 \mathrm{~cm} \times 80 \mathrm{~cm}$ is a formidable and costly challenge so IBS coatings are only used on NIF front end small-aperture $(<150 \mathrm{~mm})$ optics. One of the problems associated with e-beam coatings is humidity-induced shifting of spectral characteristics and stress. These effects can be overcome for a specific humidity range by proper centering and tuning of the deposition parameters. ${ }^{3-5}$ IBS coatings are environmentally stable so are used extensively for NIF small optics, particularly mirrors and polarizers to maintain wavefront and power (spectral) stability.

\section{LASER RESISTANCE}

Hafnia and silica are the most common coating materials for laser resistance of optical multilayer coatings at $1064 \mathrm{~nm}$. The most significant improvement in laser resistance of optical multilayer mirrors during NIF coating development occurred with the use of Hafnium metal (Hf) as a starting material. ${ }^{6-7}$ The use of $\mathrm{Hf}$ metal caused a 2-3x reduction in coating defects compared to coatings deposited from Hafnium Dioxide $\left(\mathrm{HfO}_{2}\right)$, a dielectric. For an e-beam system, $\mathrm{Hf}$ can be easily formed into a solid dense plug with minimal entrapped air pockets. These air pockets are notorious defect generators when exposed to an electron beam. In contrast, achieving a dense $\mathrm{HfO}_{2}$ plug is very challenging. Defects may also be ejected from $\mathrm{HfO}_{2}$ plugs by internal stresses due to a volumetric expansion at a phase transformation that occurs between the plug boundary in contact with the water-cooled liner and the molten volume exposed to the electron beam. Finally, interfacial damage occurs at lower fluences in multilayer coatings deposited from $\mathrm{HfO}_{2}$ than coatings deposited from $\mathrm{Hf}^{8-9}$ 


\section{LASER CONDITIONING - GROWTH DETECTION}

Laser conditioning has been shown to increase the damage threshold of mirror and polarizer coatings by $>2 \mathrm{x} .{ }^{10-11}$ The laser conditioning process consists of exposing an optical coating to a low laser fluence and then gradually increasing the fluence to the specified operating fluence of the coating. One method of laser conditioning is on-line conditioning. In this technique the coatings are installed directly in the laser system being constructed and during start up of the laser the fluence is slowly increased. The main advantage of this technique is speed since all of the coatings are laser conditioned simultaneously over their entire aperture. Another conditioning method is to utilize off-line laser conditioning stations as illustrated in figure 1. The main advantage of this method is that damage problems can be detected earlier at the coating vendors for instant feedback to the coating engineers about the laser resistance of the films. In order to have laser conditioners as coating metrology tools at NIF coating vendors, systems were constructed requiring raster scanning of the optic over multiple sub-aperture exposures. For NIF size optics, a scan can take as long as 20 hours so a minimal number of conditioning steps (two or three) were instituted.

Although there is still some debate about the mechanisms of laser conditioning, ${ }^{12}$ some mechanisms are clear. Nodular defect ejections are more severe or catastrophic at higher fluence. By laser conditioning nodular defects, the majority of the ejection sites are smooth pits that are stable at fluences exceeding the ejection fluence. Nodular ejections that occur at high fluence tend to have collateral damage surrounding the ejection pit. This collateral damage remains unstable sometimes at fluences below the ejection fluence. Measurements by photothermal microscopy have illustrated that the absorption of nodular ejection pits are up to 2 orders of magnitude smaller than before the nodule is ejected. ${ }^{13}$

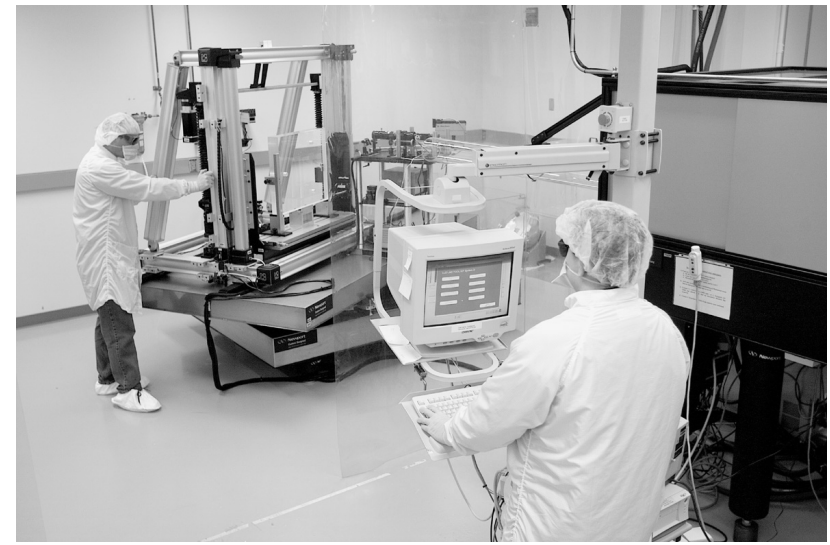

Fig. 1 Photo of an on-line laser conditioning station used to laser condition larger aperture ( up to $40 \mathrm{~cm} \times 80 \mathrm{~cm})$ mirrors and polarizers.

Photothermal measurements also illustrate that laser-conditioned defects that do not eject or visibly change also have significantly reduced absorption suggesting a defect annealing process such as improvements in stoichiometry. Photothermal microscopy experiments clearly illustrate that some defects with significant absorption may not be optically visible as opposed to nodular defects with diameters up to tens of microns in diameter that are easily observed with an optical microscope. ${ }^{14-18}$ Post mortum focused-ion beam cross section (figure 2) inspection of these defects
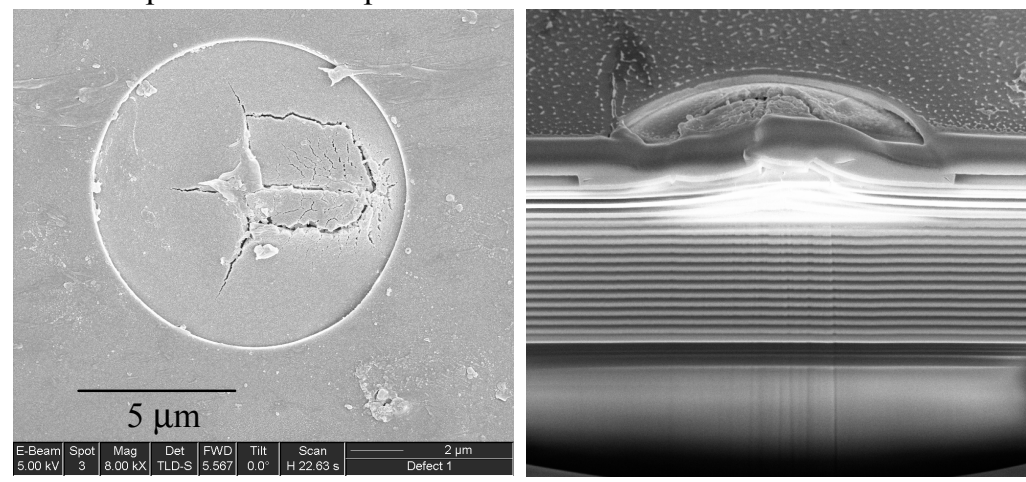

Fig. 2 Focused Ion Beam (FIB) images from above (left) and cross section (right) of a defect detected by a photothermal microscope that had no visible precursor prior to photothermal microscope inspection. The pump beam of the microscope caused the laser damage of the coating. revealed in one particular study, ${ }^{14}$ these defects had such low laser resistance that they were damaged by the pump beam of the photothermal microscope. Analysis of these images suggested a very small initiator that caused thermal-induced buckling of the surrounding multi-layer structure. These defects at this point in time are not well understood, although 351-nm laser damage studies of nanometer-size gold spheres imbedded in silica layers do confirm that extremely small highly-absorbing, imbedded defects that are not visible by optical microscopy are capable of causing significant laser damage. ${ }^{19}$ Studies of this type of defect in multilayer coatings could prove to be quite en-lightening. 


\section{MORPHOLOGY OF UNSTABLE LASER DAMAGE}

Despite all of the care taken to reduce defect sources and laser conditioning the remaining defects in a coating, a small number $(<6)$ of defects do limit the laser resistance of mirror coatings with apertures as large as $40 \mathrm{~cm} \mathrm{x} 80 \mathrm{~cm}^{20}$ To better understand what are the current fluence-limit defects, six large-aperture mirrors were damage tested and the damage morphologies were examined. After post-mortum inspection, three distinct morphologies were observed (figure 3); damage at scratches (left image), nodule ejection sites (center image), and finally catastrophic damage with no apparent detectable precursor (right image).
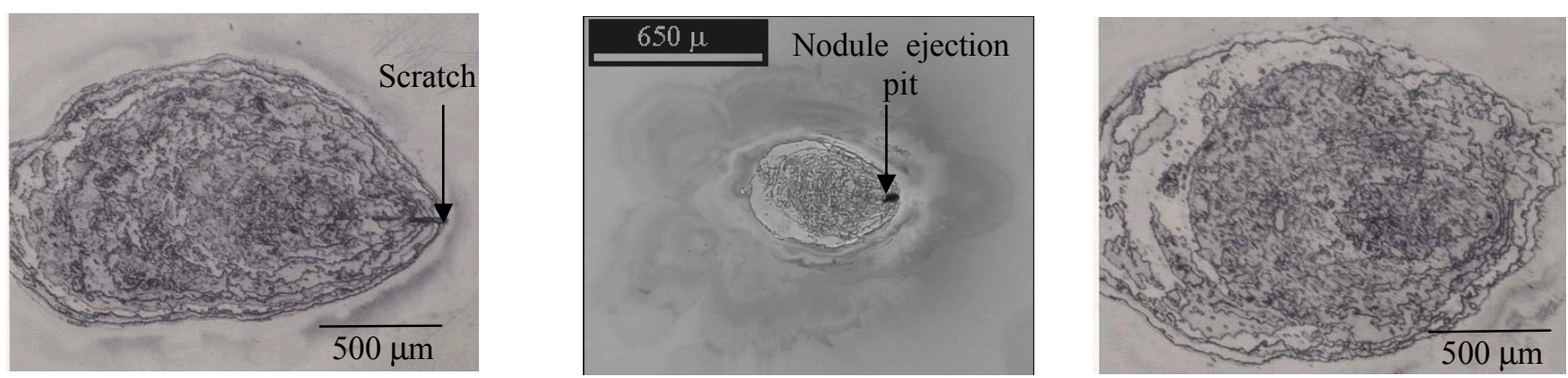

Fig. 3 Optical micrographs of unstable laser damage initiated by a scratch (left), nodule ejection (center), and no detectable precusor. All damage occurred at a fluence of $35 \mathrm{~J} / \mathrm{cm}^{2}$ with a wavelength of $1064 \mathrm{~nm}$ and pulse length of $10 \mathrm{~ns}$.

\subsection{Scratches}

Damage studies were conducted on scratches of various widths that were coated with a 1064-nm multilayer high reflector. The purpose of this study was to identify a maximum permissible substrate scratch width to quantitatively define a scratch dig specification that would yield sufficiently laser resistant mirror coatings. The scratches were generated by using a Leitz diamond tip indentor on BK7 super polished substrates. A series of six parallel scratches, separated by $5 \mathrm{~mm}$ each, were generated by translating the optic $25 \mathrm{~mm}$ while the indentor was under load. A different load was used for each substrate $-5,10$, and 25 grams, to realize a range of $<5,20-100$, and $\sim 300 \mu \mathrm{m}$ scratch widths respectively. Although this technique does generate scratched in a similar matter as grinding, polishing, and mishandling, the absence of polishing compound and cutting fluids is a considerable process departure. What this technique does provide is a reproducible method of generating nominally uniform controlled scratch widths in a small area for careful characterization. The scratched samples were cleaned in an aqueous process. A polarizer coating was deposited on the samples using $\mathrm{Hf}$ and $\mathrm{SiO}_{2}$ as the starting materials. The scratches were damage tested with a $0.9 \mathrm{~mm}$ diameter beam at $1064 \mathrm{~nm}$ with a 3-ns pulse length. The incident angle was 56 degrees. A summary of the results are plotted in figure 4.

The laser damage at scratches typically initiates at the beginning or end of the scratch. These particular scratches initiated damage at $35 \mathrm{~J} / \mathrm{cm}^{2}$ at $10 \mathrm{~ns}(1064 \mathrm{~nm})$. Interestingly much of the area of the scratch was not damaged, only the starting or ending points of the scratch. Damage also occasionally occurs at regions where the scratch suddenly gets wider.

351-nm laser damage studies of uncoated scratched fused silica substrates yield a similar trend. ${ }^{21}$ Ductile scratches with no cracking tend to have a high laser resistance while scratches formed in the brittle fracture mode tend to have extended cracking and lower laser resistance. An explanation for this behavior is cracks tend to generate significant (up to 10x) light intensification through interference of electric field waves within dielectric media. ${ }^{22}$ Unfortunately electric field studies of scratches within or under multilayer coatings have not yet been performed. Electric-field modeling within nodular defects illustrates significant light intensification occurs within the nodule and in the substrate under a defect. ${ }^{23}$ If a coating over a scratch has a similar electric field profile then there is a mechanism for getting light through the coating and into the cracks below a scratch allowing it to behave comparably to an uncoated low laser resistant crack. 


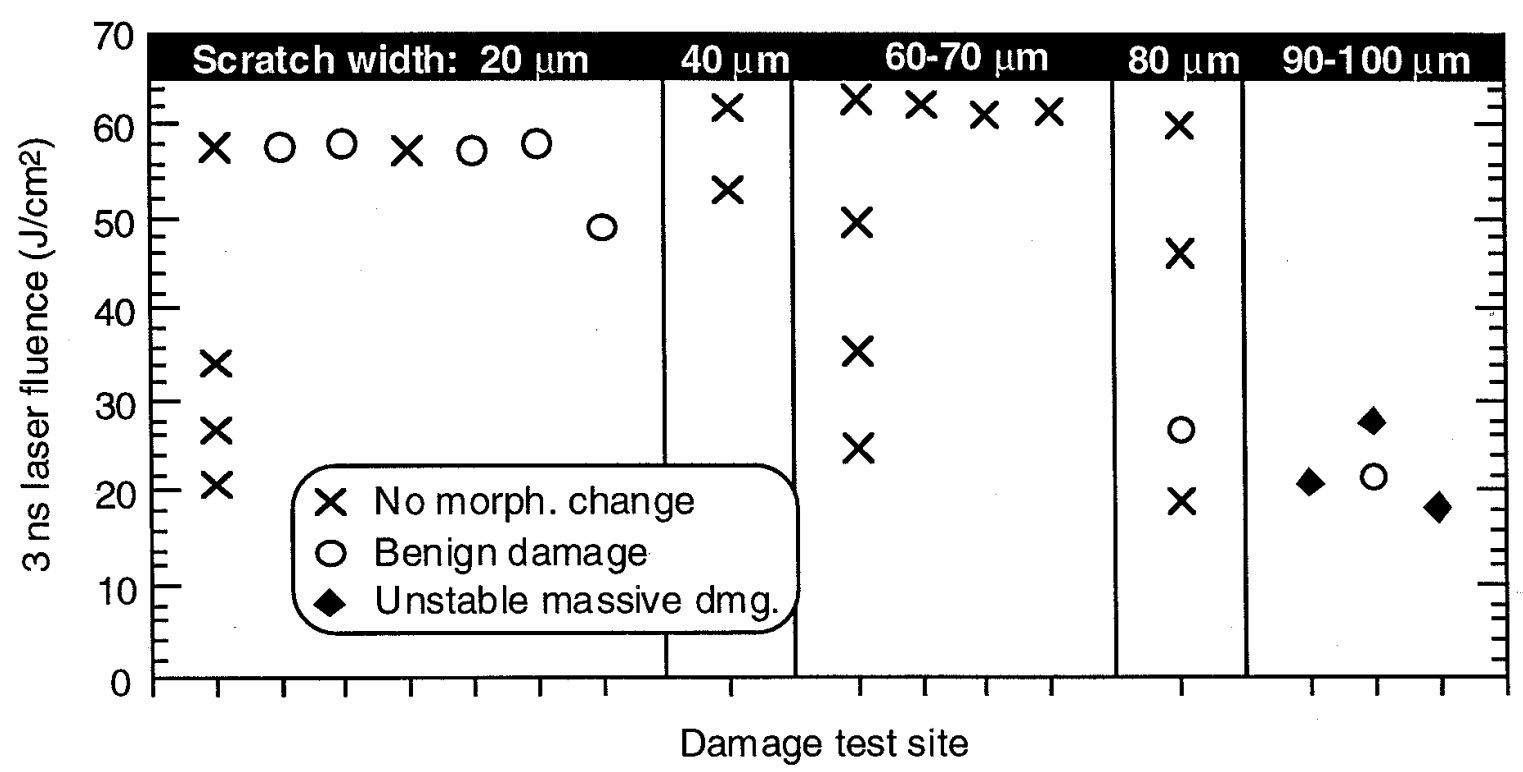

Fig. 4 Impact of scratch width on laser resistance (1064-nm irradiation with a 3-ns pulse length) of a multilayer coating. Scratches were generated on BK7 substrates using an indenter and the coatings were deposited over the scratches to determine an adequate surface quality specification for finished substrates.

\subsection{Nodules}

Although the majority of laser-conditioned nodular ejection sites are smooth pits, some sites have significant cracking and outer layer delamination around the pit. This morphology can be unstable when exposed to subsequent laser pulses resulting in damage growth that gradually strips away the multilayer creating a deepening pit while growing in diameter as illustrated in figure 3 (center). The damage growth is strongest in the direction of the incident laser irradiation. It is possible that a gentler laser conditioning protocol achieved by increasing the number of conditioning steps while simultaneously reducing the change in fluence for each step may reduce the severity of these ejections.

Typically the nodular ejection pits that are unstable when exposed to a laser are very deep. Since electric field rapidly decays through a multilayer mirror structure, electric field simulations were conducted for a range of nodular defect geometries to understand the critical parameters. ${ }^{23}$ In summary, as illustrated in figure 5, it was found that for deeplyimbedded inclusions, the electric field is maximized as inclusion diameter is increased and for incident angles of 45 degrees. Deep inclusions tend to have stronger interfaces between the nodule and multilayer so ejections tend to be more catastrophic.

\subsection{Non-visible defects}

Finally as illustrated in figure 3 (right) some catastrophic growth sites don't have a visible precursor. As suggested above, perhaps the precursor was extremely small, but highly absorbing. Regardless of the initiation source, the damage initiation site did not experience a significant change in dimension, whereas the surrounding multilayer was severely affected by subsequent laser exposure so growth ensued.

One logical question is whether these unstable damage sites have a laser resistance that is pulse length dependent such as the typical tau $=0.35$ scaling factor used for scaling damage initiation of coatings. ${ }^{24}$ To better understand this, two growth sites were damage tested on the Optical Sciences Laser (OSL) at LLNL to a pulse length range of 4 ns to 17 ns. Previous LLNL studies at $351 \mathrm{~nm}$ on damage sites in bare fused silica demonstrated little to no pulse length scaling for damage growth (i.e. damage growth occurs at the same fluence regardless of the pulse length at least in the 1-9 ns pulse length regime). Similar results were seen for optical coatings as illustrated in figure 6. 

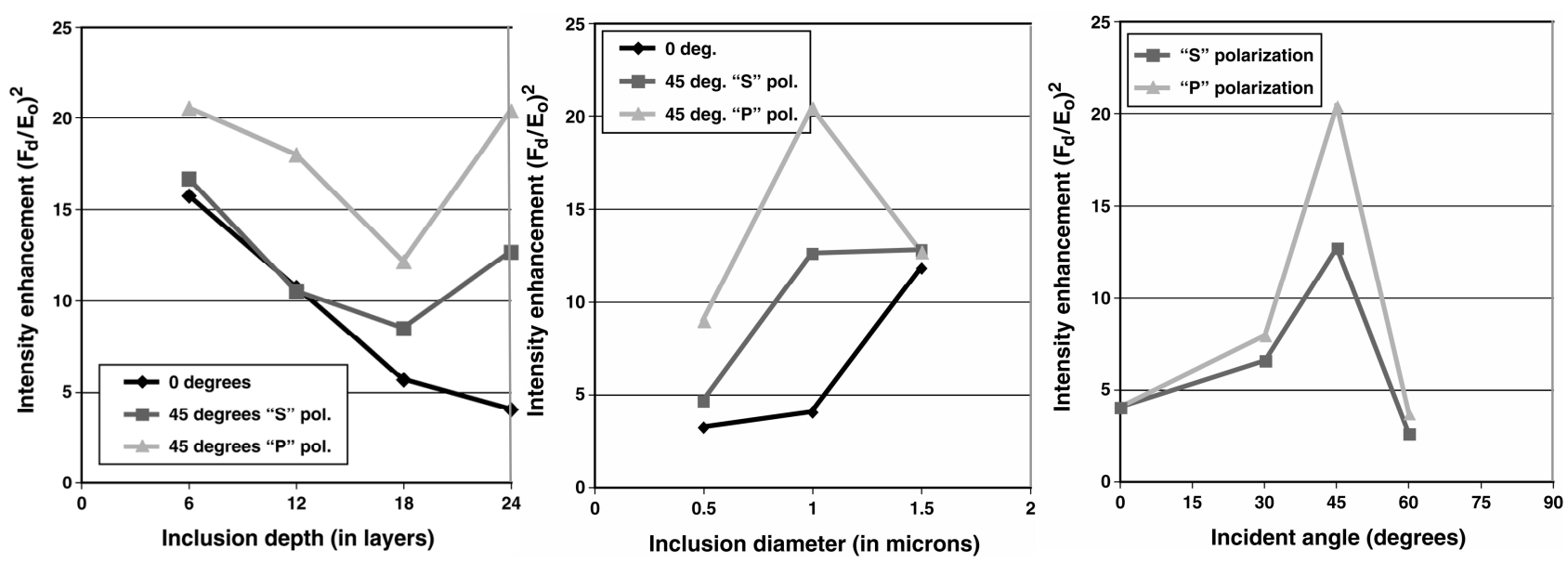

Fig. 5 Results of electric field calculations illustrate deeply imbedded $(4 \mu \mathrm{m}) 1-\mu \mathrm{m}$ inclusions can have large light intensification (left). Inclusion diameter for deeply-imbedded inclusions has an impact on light intensification (center). Finally incident angle has an impact on the light intensification of deeply-imbedded 1- $\mu \mathrm{m}$ inclusions.

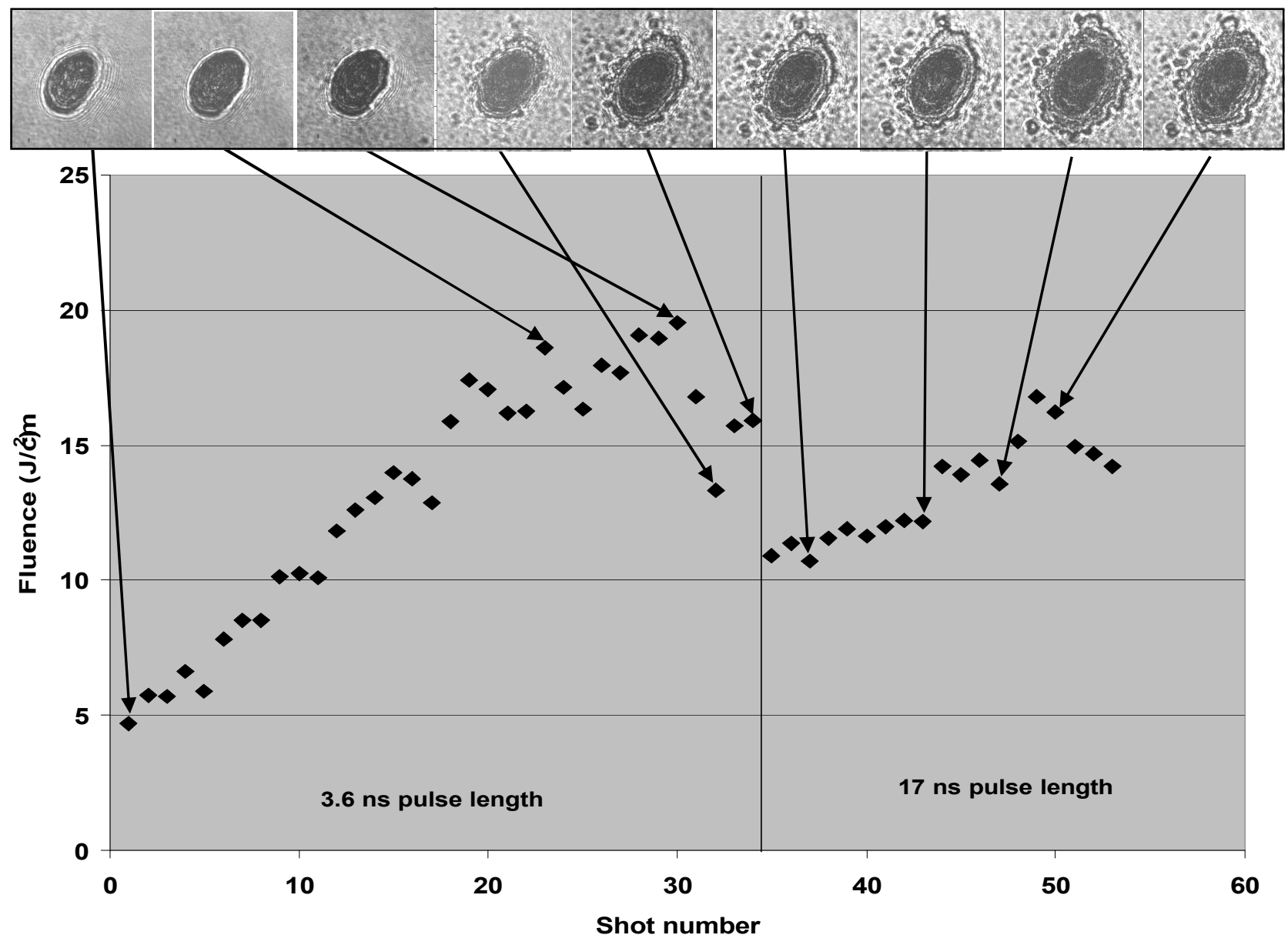

Fig. 6 Damage growth at $1064 \mathrm{~nm}$ in a multilayer mirror coating occurs at $>15 \mathrm{~J} / \mathrm{cm}^{2}$ independent of irradiation pulse length. 


\section{LASER DAMAGE MITIGATION}

If unstable damage occurs during laser conditioning or during operations on the laser system, there are few choices. Rework or scrap the optic or mitigation of the damage site to arrest the growth. A number of mitigation techniques are being investigated to stabilize laser damage in uncoated fused silica and KDP surfaces exposed to 351-nm laser irradiation. Mitigation could be an attractive option depending on defect size restrictions in the laser system, mitigation costs, and coating yields at the specified operational fluence. The three most promising techniques are exposure to a $\mathrm{CO}_{2}$ laser, ${ }^{25}$ micro-machining using a high-speed air turbine equipped with a very small single-crystal diamond bit, ${ }^{26}$ and laser ablation by a short pulse laser. ${ }^{27}$ All of these concepts are a means of removing laser damage and leaving a smooth fracture-free pit that is laser resistant. Each of these processes were also explored for mitigation of damage on high reflector coatings, although there was no significant process optimization specific to optical coatings. Namely, the processes that were developed to mitigate $351-\mathrm{nm}$ damaged uncoated surfaces were directly applied to $1053-\mathrm{nm}$ high reflector multilayer coatings.

\section{1 $\mathrm{CO}_{2}$ LASER MITIGATION}

Fused silica is absorptive to a 10.6 micron $\mathrm{CO}_{2}$ laser. Therefore, a $\mathrm{CO}_{2}$ laser beam directed to a laser damage site can melt away the rubble zone and create a smooth pit. Unfortunately, multilayers are composed of multiple materials with different absorption and thermal expansion coefficients. Therefore, our preliminary attempts with this technique were unsuccessful due to significant crazing around the damage site. Attempts to develop this technique for optical coatings (wavelength, pulse length, repetition rate, and fluence) could yield some interesting results.

\subsection{SINGLE-CRYSTAL DIAMOND MICRO-MACHINING}

A micro-machining technique using an air-turbine drill and single-crystal diamond bit as seen in figure 7 and 8 has been shown to be a particularly promising mitigation tool for damaged KDP surfaces. Initial attempts with this technology on mirror coatings were very successful for small mitigation sites. ${ }^{26}$ The air turbine shown in figure 7 , similar to a dental drill, runs on compressed air and turns at 65,000 RPM. The bits used in this study, as shown in figure 8 , were single crystal diamond bits fashioned with a negative rate appropriate for machining KDP surfaces. Single-plunge micromachined pits were produced with depths ranging from 3-15 $\mu \mathrm{m}$ in the surface of a $\mathrm{HfO}_{2} / \mathrm{SiO}_{2}$ multilayer mirror coatings on a $50-\mathrm{mm}$ round BK7 substrate. The tool was positioned about the mirror surface using high-precision translation stages equipped with sub-micron resolution stepper motors.

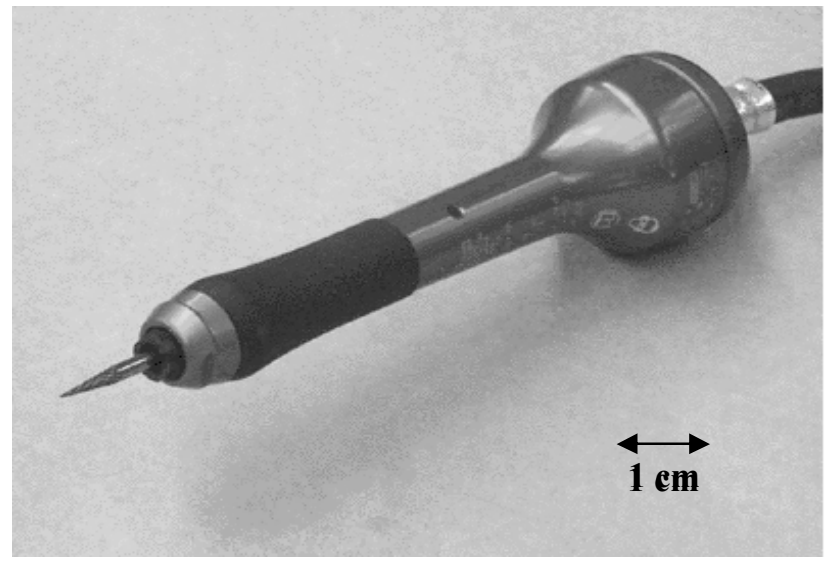

Fig 7 Air turbine used to rotate single-crystal diamond cutting tool 65,000 RPM.

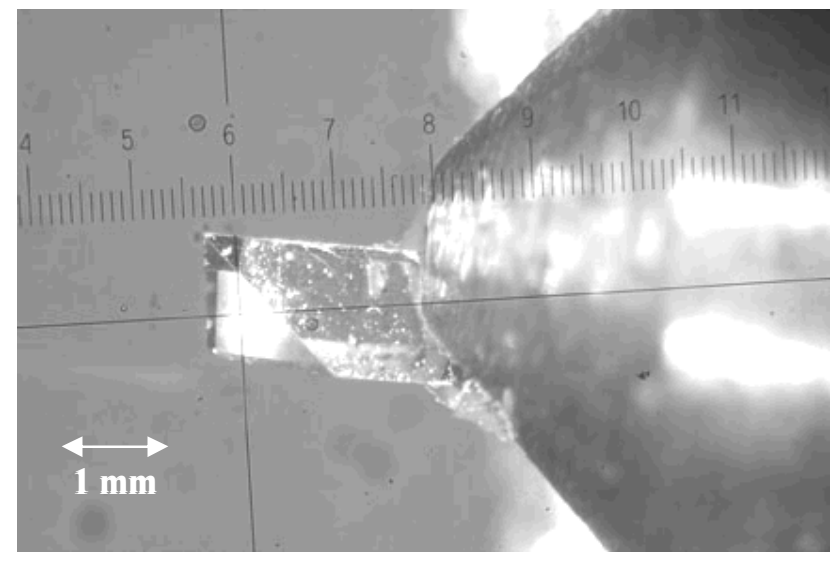

Fig 8 Single-crystal diamond cutting tool used to create mitigation sites in multilayer coatings as a technique to arrest laser damage growth.. 
An example pit is shown in figure 9. An array of pits were made on several 50-mm parts. The pits were subsequently laser damage tested through exposure to nominally 300 laser shots at a wavelength of $1053 \mathrm{~nm}$ with a 10-ns pulse length. The shots varied in fluence steps starting at about $5 \mathrm{~J} / \mathrm{cm}^{2}$ with the last 50 shots at $21 \mathrm{~J} / \mathrm{cm}^{2}$. Figure 9 (right image) shows the pit after 300 shots. As can be seen, the pit survived the damage test with no noticeable changes. This indicates that this technique may be very appropriate for small $(\sim 50 \mathrm{~mm})$ damage sites, however, damage growth is not conclusively recognized until the site is a few hundred microns in diameter. Mitigating damage sites of this size with this technique would require multiple single-plunge cuts or rastering the tool across the surface. Therefore, raster scanning the tool over a larger $(1 \mathrm{~mm} \times 1 \mathrm{~mm})$ area of the mirror surface was attempted. The findings were that the region where the diamond tool enters the surface is an extremely smooth cut with no fracturing or tearing of the coating, however, on the exit side of the rastered sites the tool produced fractures and chips. These exit side fractures and chips proved to have laser resistance and growth threshold that were only slightly better than an unmitigated damage site. Other tool cutting patterns that would leave no damage to the coating in the exit area of the diamond tool remain to be investigated.

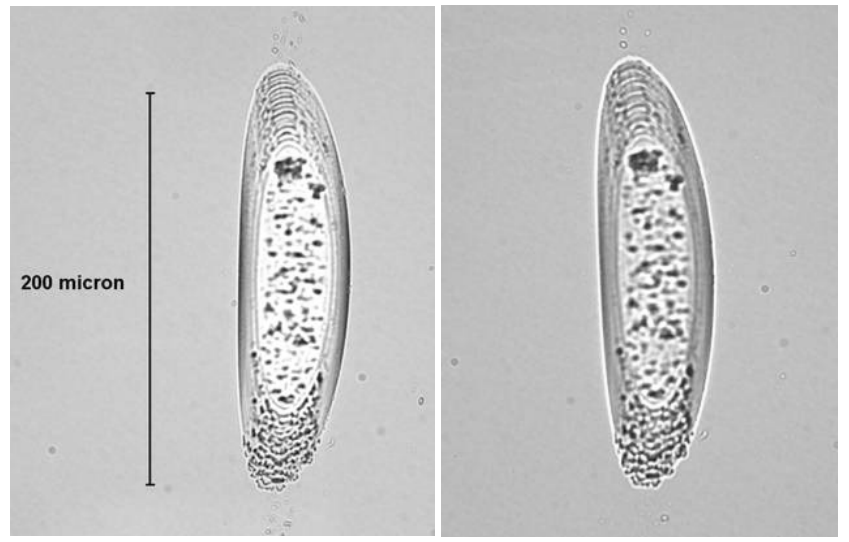

Fig. 9 Mitigation site created by a high-speed singlecrystal diamond cutting tool, before (left image) and after (right image) laser exposure at $21 \mathrm{~J} / \mathrm{cm}^{2}$ (1064 nm, 10-ns pulse length).

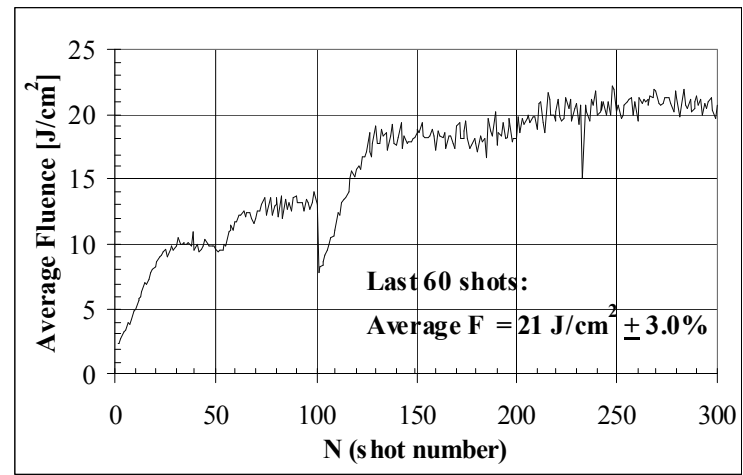

Fig. 10 History of laser shot fluence used to test the stability of a mitigation site created by a single-crystal diamond cutting tool mitigation site.

\subsection{ULTRASHORT PULSED LASER - BURST MODE}

Ultrashort pulsed lasers have been used for many different applications where minimal thermal damage is needed. A new method of drilling sensitive materials such as glass has been developed that uses an amplified burst of short $(\sim 1 \mathrm{ps})$ pulses. Single ultrashort pulses lead to delamination and other defects in dielectric layers when we attempted using them. We hypothesized that the burst-mode machining may have a better balance of material removal and thermal deposition. Single ultrashort pulses are extremely energetic and remove material cleanly, but can leave behind cracked and shocked materials, especially in transparent dielectrics. With similar, but lower energy pulses delivered at $133-\mathrm{MHz}$, there is a fair amount of residual thermal energy maintained in the material when the bursts are 100's of nanoseconds to a few microseconds in duration. This allows materials such as glass to flow and heal instead of crack and shatter. It appears that the initial tests using the burst-mode pulses are promising, but in need of further investigation.

Pits created with this technology illustrated in figure 11 were stable to $>46 \mathrm{~J} / \mathrm{cm}^{2}$ at $10 \mathrm{~ns}$ so are very promising. Unfortunately short pulse lasers are an emerging technology. Setting up a system with sufficient energy and beam diameters in the

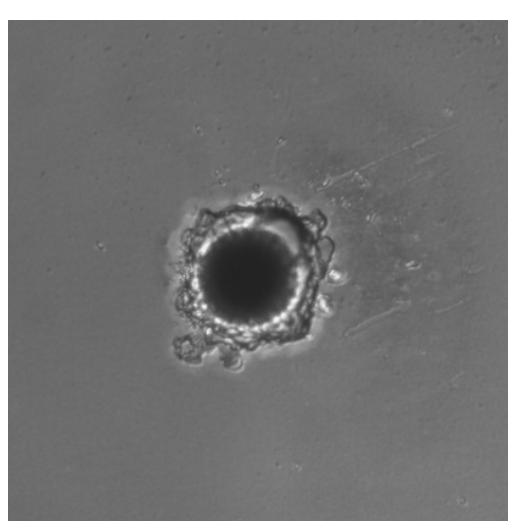

Fig.11 Ultrashort pulse burst mode mitigation site shows no change after exposure to $>46 \mathrm{~J} / \mathrm{cm}^{2}$ at $10 \mathrm{~ns}$ and $1064 \mathrm{~nm}$. 
hundreds of microns to ablate the optical coatings with a commercially available laser is a challenging problem at this time.

\section{CONCLUSIONS}

Defect reduction through the use of $\mathrm{Hf}$ as a starting material has improved the laser resistance of mirror and polarizer optical multilayer coatings. Laser conditioning has been successfully used to improve the laser resistance of largeaperture mirror and polarizer coatings. Mitigation techniques such as a high speed single-point diamond drilling tool or short pulse lasers are showing promise of arresting damage growth to improve laser resistance and extend coating operational lifetime.

\section{AKNOWLEDGEMENTS}

The authors would like to acknowledge the support of Alene Clasen in preparing this manuscript. The authors would also like to acknowledge the contributions of Robin Marjoribanks at The University of Toronto for creating the bust-mode pits, Larry Hrubesh from LLNL for creating the initial diamond bit pits, and Ron Bevis and Fred San Agustin from Spectra-Physics for performing some of the damage testing. This work was performed under the auspices of the U. S. Department of Energy by the University of California, Lawrence Livermore National Laboratory under Contract No. W7405-Eng-48.

\section{REFERENCES}

1. E. I. Moses, J. H. Campbell, C. J. Stolz, and C. R. Wuest, "The National Ignition Facility: the world's largest optics and laser system," in Optical Engineering at the Lawrence Livermore National Laboratory, T. T. Saito and M. A. Lane, eds., Proc. SPIE 5001, 1-15 (2003).

2. C. J. Stolz, C. L. Weinzapfel, A. L. Rigatti, J. B. Oliver, J. Taniguchi, R. P. Bevis, and J. S. Rajasansi, "Fabrication of meter-scale laser resistant mirrors for the National Ignition Facility, a fusion laser," in Advances in Mirror Technology for X-ray, EUVL, Lasers and Other Applications, A. M. Khounsary, U. Dinger, and K. Ota, eds., Proc. SPIE 5193, 50-58 (2003).

3. J. F. Anzellotti, D. J. Smith, R. J. Sczupak, and Z. R. Chrzan, "Stress and environmental shift characteristics of $\mathrm{HfO}_{2} / \mathrm{SiO}_{2}$ multilayer coatings", in Laser-Induced Damage in Optical Materials:1996, H. E. Bennett, A. H. Guenther, M. R. Kozlowski, B. E. Newnam, and M. J. Soileau, eds., Proc. SPIE 2966, 258-264 (1997).

4. H. Leplan, B. Geenen, J. Y. Robic, and Y. Pauleau, "Residual stresses in silicon dioxide thin films: Correlation with deposition parameters and aging behavior", J. Appl. Phys. 78, 962-967 (1995).

5. H. Leplan, J. Y. Robic, and Y. Pauleau, "Kinetics of residual stress evolution in evaporated silicon dioxide films exposed to room air", J. Appl. Phys. 79, 6926-6931 (1996).

6. C. J. Stolz, L. M. Sheehan, M. K. Von Gunten, R. P. Bevis, and D. J. Smith, "The advantages of evaporation of hafnium in a reactive environment to manufacture high damage threshold multilayer coatings by electron-beam deposition", in Advances in Optical Interference Coatings, C. Amra and H. A. Macleod, eds., Proc. SPIE 3738, 318324 (1999).

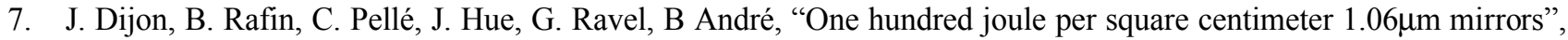
in Laser-Induced Damage in Optical Materials: 1999, G. J. Exarhos, A. H. Guenther, M. R. Kozlowski, K. L. Lewis, and M. J. Soileau, eds., Proc. SPIE 3902, 158-167 (2000).

8. J. Dijon, M. Poulingue, J. Hue, "Thermomechanical model of mirror laser damage at $1.06 \mathrm{~mm}$. Part 2: flat bottom pits formation", in Laser-Induced Damage in Optical Materials: 1998, G. J. Exarhos, A. H. Guenther, M. R. Kozlowski, K. L. Lewis, and M. J. Soileau, eds., Proc. SPIE Eng. 3578, 398-407 (1999).

9. S. C. Weakley, C. J. Stolz, Z. L. Wu, R. P. Bevis, and M. K. Von Gunten "Role of starting material composition in interfacial damage morphology of hafnia silica multilayer coatings", in Laser-Induced Damage in Optical Materials: 1998, G. J. Exarhos, A. H. Guenther, M. R. Kozlowski, K. L. Lewis, and M. J. Soileau, eds., Proc. SPIE Eng. 3578, 137-143 (1999). 
10. M. R. Kozlowski, C. R. Wolfe, M. C. Staggs, J. H. and Campbell, "Large-area laser conditioning of dielectric thin film mirrors," in Laser-Induced Damage in Optical Materials: 1989, H. E. Bennett, L. L. Chase, A. H. Guenther, B. E. Newnam, and M. J. Soileau, eds., Proc. SPIE 1438, 376-390 (1990).

11. C. J. Stolz, L. M. Sheehan, S. M. Maricle, S. Schwartz, and J. Hue, "A study of laser conditioning methods of hafnia silica multilayer mirrors", in Laser-Induced Damage in Optical Materials: 1998, G. J. Exarhos, A. H. Guenther, M. R. Kozlowski, K. L. Lewis, and M. J. Soileau, eds., Proc. SPIE Eng. 3578, 144-152 (1999).

12. H. Bercegol, "What is laser conditioning? A review focused on dielectric multilayers", in Laser-Induced Damage in Optical Materials: 1998, G. J. Exarhos, A. H. Guenther, M. R. Kozlowski, K. L. Lewis, and M. J. Soileau, eds., Proc. SPIE Eng. 3578, 421-425 (1999).

13. A. B. Papandrew, C. J. Stolz, Z. L. Wu, G. E. Loomis, S. Falabella, "Laser conditioning characterization and damage threshold prediction of hafnia/silica multilayer mirrors by photothermal microscopy," in Laser-Induced Damage in Optical Materials: 2000, G. J. Exarhos, A. H. Guenther, M. R. Kozlowski, K. L. Lewis, and M. J. Soileau, eds., Proc. SPIE 4347, 53-61 (2001).

14. C. J. Stolz, D. J. Chinn, R. D. Huber, C. L. Weinzapfel, and Z. L. Wu, "Photothermal multi-pixel imaging microscope", in Laser-Induced Damage in Optical Materials: 2003, G. J. Exarhos, A. H. Guenther, N. Kaiser, K. L. Lewis, M. J. Soileau, and C. J. Stolz, eds., Proc. SPIE 5273, 141-155 (2004).

15. M. Commandré, P. Roche, "Characterization of absorption by photothermal deflection", in Thin Films for Optical Systems, F. R. Flory, ed., Marcel Dekker, New York, 329-365 (1995).

16. A. Fornier, C. Cordillot, D. Bernardino, O. Lam, A. Roussel, C. Amra, L. Escoubas, G. Albrand, M. Commandré, P. Roche, M. Cathelinaud, and A. Gatto, "Characterization of optical coatings: Damage threshold/local absorption correlation", in Laser-Induced Damage in Optical Materials:1996, H. E. Bennett, A. H. Guenther, M. R. Kozlowski, B. E. Newnam, and M. J. Soileau, eds., Proc. SPIE 2966, 292-305 (1997).

17. M. Reichling, A. Bodemann, and N. Kaiser, "Defect-induced laser damage in oxide multi-layer coatings for 248 nm", Thin Solid Films 320, 264-279 (1998).

18. Z. L. Wu, C. J. Stolz, S. C. Weakley, J. D. Hughes, and Q. Zhao, "Damage threshold prediction of hafnia-silica multilayer coatings by nondestructive evaluation of fluence-limiting defects," Appl. Opt. 40, 1897-1906 (2001).

19. S. Papernov and A. W. Schmid, "High-spatial-resolution studies of UV-laser-damage morphology in $\mathrm{SiO}_{2}$ thin films with artificial defects", in Laser-Induced Damage in Optical Materials: 2004, G. J. Exarhos, A. H. Guenther, N. Kaiser, K. L. Lewis, M. J. Soileau, and C. J. Stolz, eds., Proc. SPIE 5647, 141-155 (2005).

20. J. Taniguchi, N. E, LeBarron, D. J. Smith, C. J. Stolz, C. L. Weinzapfel, and J. F. Kimmons, "Functional damage thresholds of hafnia/silica coating designs for the NIF laser", in Laser-Induced Damage in Optical Materials: 2000, G. J. Exarhos, A. H. Guenther, M. R. Kozlowski, K. L. Lewis, and M. J. Soileau, eds., Proc. SPIE 4347, 109-117 (2001).

21. A. Salleo, F. Y. Génin, J. M. Yoshiyama, C. J. Stolz, and M. R. Kozlowski, "Laser-induced damage of fused silica at 355-nm initiated at scratches", in Laser-Induced Damage in Optical Materials: 1997, G. J. Exarhos, A. H. Guenther, M. R. Kozlowski, and M. J. Soileau, eds., Proc. SPIE Eng. 3244, 341-347 (1998).

22. F. Y. Génin, A. Salleo, T. V. Pistor, and L. L. Chase, "Role of light intensification by cracks in optical breakdown on surfaces", J. Opt. Soc. Am. A 18, 2607-2616 (2001).

23. C. J. Stolz, M. D. Feit, and T. V. Pistor, "Light intensification by spherical inclusions imbedded within multilayer coatings", Appl. Opt., to be published.

24. C.R. Wolfe, M. R. Kozlowski, J. H. Campbell, F. Rainer, A. J. Morgan, and R. P. Gonzales, "Laser conditioning of optical thin films," in Laser-Induced Damage in Optical Materials: 1989, H. E. Bennett, L. L. Chase, A. H. Guenther, B. E. Newnam, and M. J. Soileau, eds., Proc. SPIE 1438, 360-375 (1990).

25. R. M. Brusasco, B. M. Penetrante, J. A. Butler, S. M. Maricle, and J. Peterson, " $\mathrm{CO}_{2}$-laser polishing for reduction of 351-nm surface damage initiation in fused silica", in Laser-Induced Damage in Optical Materials: 2001, G. J. Exarhos, A. H. Guenther, K. L. Lewis, M. J. Soileau, and C. J. Stolz, eds., Proc. SPIE 4679, 34-39 (2002).

26. L. W. Hrubesh, J. J. Adams, M. D. Feit, W. D. Sell, J. A. Stanley, E. Miller, S. L. Thompson, P. K. Whitman, and R. P. Hackel, "Surface damage growth mitigation on KDP/DKDP optics using single-crystal diamond micromaching", in Laser-Induced Damage in Optical Materials: 2003, G. J. Exarhos, A. H. Guenther, N. Kaiser, K. L. Lewis, M. J. Soileau, and C. J. Stolz, eds., Proc. SPIE 5273, 273-280 (2004).

27. P. R. Herman, A. Oettl, K. P. Chen, and R. S. Majoribanks, "Laser micromachining of transparent fused silica with 1-ps pulses and pulse trains", in Commercial and Biomedical Application of Ultrafast Lasers, M. K. Reed and J. Neev eds., Proc. SPIE 3616, 148-155 (1999). 